\title{
Zingiber officinale Roscoe reduces chest pain on patients undergoing coronary angioplasty: a clinical trial
}

\author{
Afshin Hasanvand ${ }^{\oplus}$, Yahya Ebrahimi ${ }^{2}$, Asghar Mohamadi ${ }^{* *}{ }^{\circledR}$, Afshin Nazari $^{4}$ \\ ${ }^{1}$ Student Research Committee, Lorestan University of Medical Sciences, Khorramabad, Iran \\ ${ }^{2}$ Department of Cardiology, Lorestan University of Medical Sciences, Khorramabad, Iran \\ ${ }^{3}$ Razi Herbal Medicines Research Center, Lorestan University of Medical Sciences, Khorramabad, Iran \\ ${ }^{4}$ Department of Physiology and Pharmacology, Lorestan University of Medical Sciences, Khorramabad, Iran
}

\section{AR T I C L E I N F O}

Article Type:

Original Article

\section{Article History:}

Received: 16 August 2018

Accepted: 10 December 2018

\section{Keywords:}

Ginger

Herbal medicine

Medicinal plant

Preconditioning

Coronary angioplasty

PTCA

\begin{abstract}
A B S T R A C T
Introduction: Evidence from animal studies suggests that Zingiber officinale (ginger) may help prevent ischemia-reperfusion injury (IRI) in heart. The aim of the present study was to investigate the effect of ginger on inducing preconditioning on patients undergoing angioplasty. Methods: Thirty-four patients, referred for elective angioplasty, were randomly divided into the control (17 patients) and ginger groups (17 patients). Subjects in the experimental group were provided $250 \mathrm{mg}$ ginger powder in Zintoma capsules per day for 10 days, whereas those in the control group received placebo. The patients underwent percutaneous transluminal coronary angioplasty (PTCA) (One 45-second balloon inflation and 2 minutes reperfusion). Chest pain scores were assessed immediately after angioplasty and cardiac injury biomarkers were assessed 12 hours later.

Results: The average pain score during the balloon inflation in the ginger group was significantly lower than the control group $(2.1 \pm 1$ versus $3.8 \pm 1.5, P=0.04)$. Troponin I was elevated in both groups after angioplasty, but there was not any significant difference between groups in this regard ( $P=0.12$ and 0.10 , respectively).

Conclusion: The use of ginger reduces chest pain during coronary angioplasty but its effect on the release of biochemical markers of myocardial damage is obscure.
\end{abstract}

Implication for health policy/practice/research/medical education:

This Clinical trial revealed that ginger might be useful in coronary angioplasty and a candidate as a possible prospective natural drug for this purpose.

Please cite this paper as: Hasanvand A, Ebrahimi Y, Mohamadi A, Nazari A, Kouhpayeh A. Zingiber officinale Roscoe reduces chest pain on patients undergoing coronary angioplasty: a clinical trial. J Herbmed Pharmacol. 2018;9(1):47-50. doi: 10.15171/ jhp.2019.08.

\section{Introduction}

Ischemia-reperfusion injury (IRI) occurs after the treatment of myocardial infarction and other elective procedures such as open heart surgery and coronary angioplasty (1). The most important theory to reduce IRI is ischemic preconditioning (IPC) introduced by Murry et al who suggested that the short episodes of ischemiareperfusion increase myocardial tolerance to long periods of severe ischemia and reperfusion after cardiac events (2). Preconditioning has two windows of protection. The first begins immediately after the treatment and lasts for 1 to 2 hours, whereas the second begins 12 hours after ischemia and lasts for 72 to 96 hours (3). A number of approaches have been developed that mimic IPC. Some of the more important pharmacological agents that have been studied include adenosine, bradykinin and opioids (4-6).

The ginger (Zingiber officinale Roscoe) has exerted potential protective effects against IRI in animal models $(7,8)$. Ginger is a tropical plant which has been cultivated for thousands of years as a spice and medicinal purposes in South-East Asia and other parts of the world (9). Also both animal and human studies have shown that ginger have many other therapeutic effects such as antiinflammatory, antioxidant, antihypertensive, anti-platelet, positive inotropic and lowering glucose, cholesterol and other lipid profile in cardiovascular diseases (10-14). Percutaneous coronary angioplasty (PTCA) is a clinical setting with mandatory episodes of ischemia reperfusion 
and is generally believed that this model resembles experimental animal models more closely than the acute myocardial infarction clinical models (15). Therefore, the present study was designed to analyze the possible protective effect of ginger against regional ischemic reperfusion $(\mathrm{I} / \mathrm{R})$ injury in patients undergoing coronary angioplasty.

\section{Materials and Methods}

Study population

In this double blind randomized clinical trial, 34 patients (2 groups) referred for elective PTCA were randomly divided to "intervention" and "control" groups. The study was carried out in Shahid Madani Heart hospital in Khorramabad, Iran between February 2016 to December 2017. The study protocol was approved by the medical ethics research committee of Lorestan University of Medical Sciences and written informed consent was obtained from each patient. All patients had stable angina when underwent coronary angioplasty. Patients were included if they had isolated obstructive lesion in at least one coronary artery branch with $\geq 70 \%$ reduction in the luminal diameter. Patients who had allergy to ginger, episode(s) of chest pain in 48 hours before PTCA, Prinzmetal angina, conduction defects on the ECG and baseline ST-segment deviations on the surface electrocardiography (ECG) were excluded from study. Both control and ginger groups consisted of 16 patients (men and women, respectively). The last episode of chest pain in all patients occurred in 48 hours before PTCA.

\section{Study protocol}

In this double-blind randomized clinical trial each patient in the intervention (ginger) group received ginger capsules (250 mg, orally of Goldaru, Isfahan, Iran) daily and the same samples from the placebo group received starch capsules ( $250 \mathrm{mg}$, orally Goldaru, Isfahan, Iran) daily since 10 days before angioplasty. The diagnostic angiography was performed and nonionic contrast agent (Visipaque GE, Healthcare Ireland, osmolarity: $320 \mathrm{mg} /$ $\mathrm{mL}$ ) was administrated intravenously for each patient. After diagnostic angiography, the patients who had isolated obstructive lesion in at least one coronary artery branch with $\geq 70 \%$ reduction in the luminal diameter underwent coronary angioplasty. The PTCA procedure was performed by routine technique using the femoral approach: After prep and drape, heparin (2000 IU) was administered intravenously before coronary angioplasty. Then, balloon was positioned across the lesion and one session of balloon inflation was done for 45 second followed by two minute of reperfusion. The balloon inflation pressure ranged from 11 to 14 atmospheres. At the end of the procedure, angioplasty balloon deflated and was withdrawn from the stenotic site and after 2 min reperfusion the study protocol was finished. Similar procedures were done in control group. The cardiologist who applied angiography and angioplasty procedures was blind about the patient's group.

\section{Laboratory measurements}

Venous blood samples were obtained from each patient before and 12 hours following PTCA procedure to measure troponin I as biomarker of cardiac cell injury. Troponin I activities were measured by standard kits (RAMP Vancouver, Canada) using an auto-analyzer and expressed as nano gram per milliliter $(\mathrm{ng} / \mathrm{mL})$. The normal values of cardiac troponin 1 ( $\mathrm{cTnI}$ ) were considered to be $\leq 0.1$ $\mathrm{ng} / \mathrm{mL}$.

Assessment of chest pain

At the end of balloon inflation the severity of chest pain was assessed by numeric rating scale (NRS) by a nurse who had no knowledge about the patient's group. The patients were asked to say the severity of chest pain on a scale of 0 (no pain) to 10 (severe pain).

\section{Statistical analysis}

Biomarkers data are expressed as mean plus standard deviations. All chest pain score data are shown in the relevant figures and the median is also presented. Statistical analysis of data within groups was performed with the Mann-Whitney test and the changes within groups were analyzed by the Wilcoxon $t$ test. Statistical significance was defined as $P<0.05$.

\section{Results}

The demographic characteristics of the control and the intervention groups are summarized in Table 1. There were no statistically significant differences between the two groups in terms of the determined parameters. Angioplasty was successfully performed in all patients.

Table 1. Clinical characteristics of the patients in the two groups

\begin{tabular}{lcc}
\hline Variable & $\begin{array}{c}\text { Control group } \\
\text { (n) }\end{array}$ & $\begin{array}{c}\text { Intervention group } \\
\text { (n) }\end{array}$ \\
\hline Gender, M/F & $13 / 4$ & $9 / 8$ \\
Hypertension, $\mathrm{n}$ & 10 & 9 \\
Smoking, $\mathrm{n}$ & 11 & 8 \\
Diabetes mellitus, $\mathrm{n}$ & 5 & 5 \\
Previous CABG, $\mathrm{n}$ & 4 & 2 \\
Previous MI, n & 4 & 4 \\
EF above 50\% & 11 & 9 \\
EF below 50\% & 6 & 8 \\
Use of Long-acting nitrates & 4 & 1 \\
Use of beta-blocker agents & 9 & 5 \\
Glibenclamide usage & 3 & 2 \\
\hline
\end{tabular}

$\mathrm{n}=$ number of patients.

CABG: Coronary artery bypass graft; MI: myocardial infarction; EF: left ventricular ejection fraction. 
There were no statistically significant differences between the two groups in the determined parameters.

\section{Chest pain}

The average pain score during the balloon inflation in the ginger group was $2.1 \pm 1$ and in the control group was $3.8 \pm 1.5(2.1 \pm 1$ versus $3.8 \pm 1.5, P=0.04)$. The pain score between the two groups is significantly different.

\section{Cardiac biomarkers}

Troponin level changed from $1.4 \pm 1.1 \mathrm{ng} / \mathrm{mL}$ to $0.51 \pm 0.62$ in the ginger group and from $1.4 \pm 1.1$ to $0.89 \pm 0.92$ in the control group. There were no significant differences between the values of troponin I in the two groups before and after angioplasty $(P=0.10)$ (Table 2).

\section{Discussion}

The results of the present study showed that usage of 250 mg ginger during 10 days before PTCA reduces chest pain but has no effect on release of cardiac biomarkers. In some studies, troponin I has been analyzed after angioplasty as hallmarks of cardiac cell injury $(16,17)$. In these studies the relationship between biomarker changes after coronary angioplasty and the patients' outcome was assessed $(18,19)$. Ginger has a lot of valuable compounds and has used for medicinal purposes for several hundred years. In recent years the results of clinical trials indicated that ginger is an all-purpose plant in medicine field such as cardiovascular disease. In addition, it has been proposed that ginger possesses antioxidant, antiinflammatory, glucose, cholesterol and lipid-lowering, anti-platelet, hypotensive and positive inotropic effects (20-25). Based on the anti-inflammatory effect of ginger this hypothesis was extracted that ginger might be used in reducing IRI. In recent years the ginger has been a new agent determined in reducing IRI in rat kidney $(7,8)$. A number of pharmacological agents like estrogen, bradykinin and enalapril have been shown to be cardioprotective in patients undergoing PTCA by determination of ST segment changes, echocardiography findings and the severity of chest pain $(26,27)$. The present study tested the effect of ginger in reducing IRI in human heart in patients undergoing angioplasty. We measured the chest pain score and troponin values as indicators of myocardial damage. In many clinical trials the pharmacologic preconditioning reduced chest pain and release of troponin that were considered as reflects of cardio-protective effect $(26,27)$. The ST changes were not measured in the present study and the cardiac biomarkers were measured instead of ST changes values. In a similar study, oxygen was administrated prior to elective angioplasty which had no effect on cardiac biomarkers level but reduced chest pain. In that study the authors did not include a placebo and this factor could affect the accuracy of the pain score that is a subjective endpoint (28). In this study, placebo
Table 2. Serum troponin values before and after PTCA in the two groups

\begin{tabular}{lcc}
\hline $\begin{array}{l}\text { Group value (within each } \\
\text { group) }\end{array}$ & $\begin{array}{c}\text { Before PTCA } \\
\text { (mean } \pm S D \text { ),ng/ml }\end{array}$ & $\begin{array}{c}\text { After PTCA } \\
\text { (mean } \pm S D), n g / m l\end{array}$ \\
\hline Ginger group & $1.41 .1 \pm$ & $0.510 .62 \pm$ \\
Control group & $1.41 .1 \pm$ & $0.89 \pm 0.92$ \\
$P$ value & 0.12 & 0.10 \\
\hline
\end{tabular}

PTCA: Percutaneous transluminal coronary angioplasty.

was used to minimize the effects of confounding factor to measure pain score. The mechanism of ginger in reducing ischemia reperfusion injury is not fully understood but the free radical scavenger has been proposed $(7,8)$.

In conclusion the use of ginger can reduce chest pain during coronary angioplasty and because of its convenient use and no significant complications; it might be a good therapeutic agent in clinical practice.

\section{Authors' contributions}

All the authors contributed to data collection and preparation of the manuscript. The first draft was prepared by $\mathrm{AH}, \mathrm{AM}$ and $\mathrm{AK}$. All authors read the final version and confirmed for the publication.

\section{Conflict of interest}

Authors declare that there is not any conflict of interest.

\section{Ethical considerations}

Ethical issues including text plagiarism, manipulation or appropriation, data fabrication, falsification, redundant publication as well as duplicate submissions have been carefully observed by authors. The protocol was confirmed by medical ethics research committee of Lorestan University of Medical Sciences (IR.LUMS.RES. 1396. 261) and written informed consent was obtained from each patient.

\section{Funding/Support}

This study was conducted with financial support of the research departments of Lorestan University of Medical Sciences (Code number: 374).

\section{References}

1. Murphy E, Steenbergen C. Mechanisms underlying acute protection from cardiac ischemia-reperfusion injury. Physiol Rev. 2008;88(2):581-609. doi: 10.1152/ physrev.00024.2007.

2. Murry CE, Jennings RB, Reimer KA. Preconditioning with ischemia: a delay of lethal cell injury in ischemic myocardium. Circulation. 1986;74(5):1124-36.

3. Bolli R. The late phase of preconditioning. Circ Res. 2000;87(11):972-83.

4. Dana A, Skarli M, Papakrivopoulou J, Yellon DM. Adenosine $\mathrm{A}(1)$ receptor induced delayed preconditioning in rabbits: induction of $\mathrm{p} 38$ mitogen-activated protein kinase activation and Hsp27 phosphorylation via a tyrosine 
kinase- and protein kinase C-dependent mechanism. Circ Res. 2000;86(9):989-97.

5. Baxter GF, Ebrahim Z. Role of bradykinin in preconditioning and protection of the ischaemic myocardium. Br J Pharmacol. 2002;135(4):843-54. doi: 10.1038/sj.bjp.0704548.

6. Kodani E, Xuan YT, Shinmura K, Takano H, Tang XL, Bolli R. Delta-opioid receptor-induced late preconditioning is mediated by cyclooxygenase- 2 in conscious rabbits. Am J Physiol Heart Circ Physiol. 2002;283(5):H1943-57. doi: 10.1152/ajpheart.00150.2002.

7. Maghsoudi S, Gol A, Dabiri S, Javadi A. Preventive effect of ginger (Zingiber officinale) pretreatment on renal ischemiareperfusion in rats. Eur Surg Res. 2011;46(1):45-51. doi: $10.1159 / 000321704$.

8. Uz E, Karatas OF, Mete E, Bayrak R, Bayrak O, Atmaca AF, et al. The effect of dietary ginger (Zingiber officinals Rosc) on renal ischemia/reperfusion injury in rat kidneys. Ren Fail. 2009;31(4):251-60. doi: 10.1080/08860220902779921.

9. Physicians Desk Reference for Herbal Medicines. Montvale, New Jersey, USA: Thomson; 2004.

10. Grzanna R, Lindmark L, Frondoza CG. Ginger--an herbal medicinal product with broad anti-inflammatory actions. J Med Food. 2005;8(2):125-32. doi: 10.1089/jmf.2005.8.125.

11. Ahmed RS, Seth V, Banerjee BD. Influence of dietary ginger (Zingiber officinales Rosc) on antioxidant defense system in rat: comparison with ascorbic acid. Indian J Exp Biol. 2000;38(6):604-6.

12. Verma SK, Singh M, Jain P, Bordia A. Protective effect of ginger, Zingiber officinale Rosc on experimental atherosclerosis in rabbits. Indian J Exp Biol. 2004;42(7):7368.

13. Ghayur MN, Gilani AH. Ginger lowers blood pressure through blockade of voltage-dependent calcium channels. J Cardiovasc Pharmacol. 2005;45(1):74-80.

14. Kobayashi M, Ishida Y, Shoji N, Ohizumi Y. Cardiotonic action of [8]-gingerol, an activator of the Ca++-pumping adenosine triphosphatase of sarcoplasmic reticulum, in guinea pig atrial muscle. J Pharmacol Exp Ther. 1988;246(2):667-73.

15. Leesar MA, Stoddard MF, Dawn B, Jasti VG, Masden R, Bolli R. Delayed preconditioning-mimetic action of nitroglycerin in patients undergoing coronary angioplasty. Circulation. 2001;103(24):2935-41.

16. Jaffe AS, Babuin L, Apple FS. Biomarkers in acute cardiac disease: the present and the future. J Am Coll Cardiol. 2006;48(1):1-11. doi: 10.1016/j.jacc.2006.02.056.

17. Salehi R, Alizadeh Asl A, Salehi A, Azarfarin R. The changes of cardiac troponin I and creatine kinase MB isoenzyme after percutaneous transluminal coronary angioplasty. J
Cardiovasc Thorac Res. 2009;1(1):11-5.

18. Okmen E, Cam N, Sanli A, Unal S, Tartan Z, Vural M. Cardiac troponin I increase after successful percutaneous coronary angioplasty: predictors and long-term prognostic value. Angiology. 2006;57(2):161-9. doi: $10.1177 / 000331970605700205$.

19. Ghaemian A, Shiraj H. Measuring cardiac biomarkers after angioplasty and their prognostic value. J Mazandaran Univ Med Sci. 2012;21(1):344-52.

20. Bordia A, Verma SK, Srivastava KC. Effect of ginger (Zingiber officinale Rosc.) and fenugreek (Trigonella foenumgraecum L.) on blood lipids, blood sugar and platelet aggregation in patients with coronary artery disease. Prostaglandins Leukot Essent Fatty Acids. 1997;56(5):379-84.

21. Fuhrman B, Rosenblat M, Hayek T, Coleman R, Aviram M. Ginger extract consumption reduces plasma cholesterol, inhibits LDL oxidation and attenuates development of atherosclerosis in atherosclerotic, apolipoprotein E-deficient mice. J Nutr. 2000;130(5):1124-31. doi: 10.1093/ jn/130.5.1124.

22. Verma SK, Singh M, Jain P, Bordia A. Protective effect of ginger, Zingiber officinale Rosc on experimental atherosclerosis in rabbits. Indian $J$ Exp Biol. 2004;42(7):736-8.

23. Srivastava KC, Mustafa T. Ginger (Zingiber officinale) and rheumatic disorders. Med Hypotheses. 1989;29(1):25-8.

24. Young HY, Luo YL, Cheng HY, Hsieh WC, Liao JC, Peng WH. Analgesic and anti-inflammatory activities of [6]-gingerol. J Ethnopharmacol. 2005;96(1-2):207-10. doi: 10.1016/j.jep.2004.09.009.

25. Thomson M, Al-Qattan KK, Al-Sawan SM, Alnaqeeb MA, Khan I, Ali M. The use of ginger (Zingiber officinale Rosc.) as a potential anti-inflammatory and antithrombotic agent. Prostaglandins Leukot Essent Fatty Acids. 2002;67(6):4758.

26. Lee TM, Su SF, Chou TF, Tsai CH. Pharmacologic preconditioning of estrogen by activation of the myocardial adenosine triphosphate-sensitive potassium channel in patients undergoing coronary angioplasty. J Am Coll Cardiol. 2002;39(5):871-7.

27. Leesar MA, Stoddard MF, Manchikalapudi S, Bolli R. Bradykinin-induced preconditioning in patients undergoing coronary angioplasty. J Am Coll Cardiol. 1999;34(3):639-50.

28. Mohammadi A, Raoufi S, Namdari M, Raoufi A, Anbari K, Tahzibi S, et al. Pre-exposure to normobaric hyperoxia has no effect on myocardial injury biomarkers after percutaneous transluminal coronary angioplasty. Iranian Heart Journal. 2016;17(3):18-26. 